\title{
Preface to the First Edition
}

This book is the text, substantially unaltered though slightly enlarged, revised and annotated, of the three lectures I gave in New Brunswick in April, as the first of the Mason Welch Gross Lectures. The theme, and in a way the manner, reflect the occasion: it seemed to me appropriate that I should speak professionally, as an ancient historian, but at the same time bring the ancient (Greek) experience to bear on the subject of a major contemporary discussion, the theory of democracy. This kind of discourse, once not uncommon, has fallen into desuetude. The interest shown by the Rutgers audience, at least, suggests that I am not wrong in thinking that it is a legitimate, even fruitful, kind of discourse.

The opportunity I was given to initiate this new lecture series was an unexpected and most welcome honour, above all because it permitted me to share in a tribute to Mason Gross, whom I have known and admired for many years (and who is a member of my Cambridge College). The eight days my wife and I spent in New Brunswick and Newark, after an absence of twenty years, could not possibly be surpassed in warmth and friendliness. I trust I shall be forgiven if I single out for particular thanks our hosts, Dick and Suzanne Schlatter in New Brunswick, Horace De Podwin in Newark, and do not go on to name the other old friends and former students who contributed to the festivity.

I must also express my gratitude to my friend and colleague, Quentin Skinner of Christ's College, for his invaluable counsel at 
several stages in the preparation of this book; and, as with all my books, to the help of my wife.

M.I.F.

Jesus College, Cambridge

July 24, 1972 
Democracy Ancient and Modern 
